\title{
Reading signs: Semiotics and depth psychology
}

INNA SEMETSKY

Abstract

This article brings together C. S. Peirce's semiotics, Jung's analytical psychology, and the ancient system of Tarot. When interpreted, Tarot images create a narrative that represents a process of individuation based on the integration of the unconscious into consciousness. The interpretation is based on a semiotic code constituting the "language of signs" structured in accord with Peirce's genuine triad. The therapeutic function of Tarot readings consists in the transformation of habits and discovering meanings in experience.

The article presents Tarot typology in general, and specifically focuses on a documented case study for "Marina," who consented to having her case discussed and published. The reading and interpretation of signs at the deep level of Marina's psyche brings many unconscious feelings to the level of conscious awareness. The new level of self-awareness empowers Marina with the ability to choose a novel course of action and achieve emotional security. Such a transformative effect would have been impossible in the absence of Tarot that provides an unorthodox epistemic access to the semiotic reality, thereby confirming Peirce's insight that all cognition is sign-mediated.

Keywords: meaningful experience; Jung; Peirce; the language of signs; Tarot; transformation of habits.

\section{Introduction}

This article brings together Charles Sanders Peirce's semiotics as a science of signs and Carl Jung's archetypal psychology. For both, a customary direct cause-effect link is insufficient to explain the meaningfulness of the seemingly disconnected events. An event has to make sense and be 
meaningful not because of such-and-such cause bringing about this or that effect, but because of the specific sign-relation embedded in the meaningful coincidences between real-life events and the collective unconscious. Mechanistic causality gives way to an acausal connecting principle, called synchronicity by Jung, and it is an interpretation or mediation in analysis that brings forth the significance of an event. This paper asserts that quite a similar logic is applied to the process of reading signs in the modality of interpreting the meanings of Tarot images, and as a practical embodiment of such logic of the included middle constituting Peirce's triadic semiotics, this paper describes a case study represented by one actual Tarot reading for "Marina" who consented to having her case documented and published. ${ }^{1}$

Briefly, a Tarot deck consists of seventy-eight pictorial cards that present information in an iconic format. The pictures on the cards resemble illustrations to a fairy tale or an adventure story. This is the story of an individual journey through life with its many events and experiences that constitute what Jung called the process of individuation. The aim of the individuation is the integration of conscious and unconscious aspects of one's life for the purpose of achieving a "greater personality" (Jung CW 7: 136): the culmination of the process is represented by the actualized archetype of the Self. The essential identity of human experiences reflected in worldwide myths and folklore led Jung to postulate the existence of the collective unconscious or objective psyche shared at a deeper level by all members of the humankind that manifests itself through archetypal, symbolic and latent, images (Jung 1959). The twenty-two so called Major Arcana in the Tarot deck represent the archetypes of the collective unconscious. The remaining fifty-six Minor cards represent a spectrum of typical situations, each accompanied by a certain mood, affect, thought, and behavior. The constellation of images in a typical Tarot layout comprises, in a symbolic form, multiple spiritual lessons that a human soul must learn in order to be fruitful and creative in its experiential encounters.

For Jung, the profound relationship of the soul of the world, Anima Mundi, with an individual human consciousness remained a great mystery. The true means of communication between the conscious mind and the unconscious is a system of signs as a language-substitute; a symbolic extra-linguistic means of communication. It is the Tarot symbolism the universal language of signs (Semetsky 2006) - that establishes such an unorthodox communicative link as the included middle - an interpretant - in a Peircean genuine, triadic sign. The meanings of the symbols embedded in pictures are not arbitrary but accord with the semiotic code (cf. Noth 1995) of this universal language. A Tarot reader translates the 
pictorial language of symbols and signs into a spoken word. Many typical life experiences are represented in the patterns that appear when the cards are being spread in this or that layout. As themes emerge in the course of a reading, therapeutic material is being collected. This material contributes to the healing of one's psyche as it provides a much-sought guidance toward solving a variety of problems or clarifying an ambiguous situation. In terms of the archetypal dynamics, Tarot - despite being traditionally considered irrational and illogical - helps us to achieve a much wider scope of awareness than rational thinking as deductive reasoning from premise to conclusion is capable of providing.

Tarot symbols hold together contents that intellect alone is incapable of; such is what Jung called a transcendent, symbolic function. By bringing to awareness many initially unperceived meanings, Tarot readings perform this function and contribute to making the unconscious material conscious. The Tarot images are projections ${ }^{2}$ of human desires, wishes, beliefs, and hopes, and the power of Tarot symbolism is such that the images transcend and move beyond and above existing blocks and defenses, thus fulfilling a prospective function. Because of the synthesizing nature of symbols, the meanings expressed in the multitude of unconscious images can be interpreted, elucidated, and potentially integrated into consciousness. Many contemporary post-Jungians indeed explore the Tarot symbolism. Andrew Samuels mentions "systems such as that of the I Ching, Tarot and astrology" (1985: 123) among the resources in analysis and quotes Jung writing in 1945: "I found the I Ching very interesting ... I have not used it for more than two years now, feeling that one must learn ... or try to discover (as when one is learning to swim) whether the water will carry one (quoted in Jaffe 1979)" (Samuels 1985: 123). Jung's biographer Laurens van der Post notices the contribution made to analytical psychology by Nichols' (1980) in her illuminating investigation of Tarot as a means for expanding human perceptions. Irene Gad (1994) connected Tarot cards with the process of individuation and considered their archetypal images "to be ... trigger symbols, appearing and disappearing throughout history in times of transition and need" (1994: xxxiv).

\section{Jung's archetypes and Peirce's signs ${ }^{3}$}

Charles Sanders Peirce's posited logic as semiotics, that is, a science of signs, presented in a form of three basic categories, Firstness, Secondness, and Thirdness, the functioning of which can be related to Jungian analytic process. In psychological terms, "Feeling is First, Sense of reaction Second, General conception Third, or mediation" ( $C P$ 6.7). It is mediation 
or interpretation that creates a meaning for a sign. In metaphysical terms, mind and matter do not oppose each other but can be reconciled by virtue of a developmental evolutionary process: "Mind is First, Matter is Second, Evolution is Third" (CP 6.7). Similar to Peirce, Jung rejected dualistic split and asserted that "psyche and matter are two different aspects of one and the same thing" (Jung CW 8: 418). Agreeing with ancient esoteric philosophies, Jung did not draw a line of great divide between the products of imagination and those of the intellect: all thinking aims to the creation of meanings. A sign, for Peirce, can be represented by image, index or symbol, and a perfect sign combines all three semiotic elements, so that image (or icon) is always already present in the products of the intellect such as concepts, meanings and judgments.

In its practical sense, Jungian analysis incorporates "the paradigm of an active, interventionist therapist" (Samuels 1985: 197) who facilitates an analytic session by means of interpreting images that appear as unconscious material in the analysand's dreams, or in art forms like pictures and drawings, including such artifacts as I Ching and Tarot, or in the course of active imagination during sessions. The unconscious, for Jung, is specified as lacking meaning, that is, staying out of the conscious awareness prior to interpretation or mediation. Analogously, a sign, for Peirce, is in fact the sign if and when it is interpreted, and a genuine sign always has a triadic structure, the Thirdness functioning as an interpretant, which intervenes (as in the analytical practice) between a sign per se and its object according to the diagram (Figure 1).

A sign, "in order to fulfil its office, to actualize its potency, must be compelled by its object" (CP 5. 554), therefore it strives to appear in a mode of Thirdness and become available to integration into consciousness. For Jung, all archetypal images are "endowed with a generative power ... [the image] is psychically compelling" (Samuels, Shorter and Plaut 1986: 73). An act of imagination is potentially transformative, according to Peirce, in its function as deliberation for the purpose to generate a meaning for a habit. Habits are dispositions to act in a certain

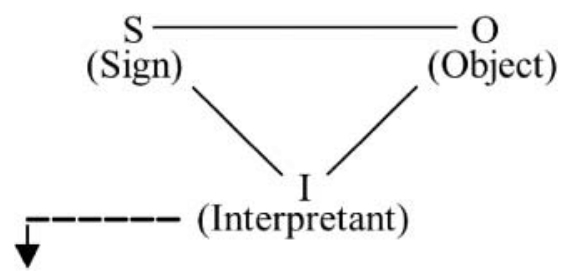

Figure 1. Triadic sign 
way under specific circumstances "and when actuated by a given motive" (CP 5.480). As for the archetypes, Jung considered them to be like a force charged with energy and "system[s] of readiness for action" (Jung CW 9: 199). The unconscious permeated by the archetypes is collective; it involves past heritage and future possibilities; and its content is determined by the activity of the archetypal dynamical patterns as "habits-taking" (CP 1.409) that manifest as universal motifs in human behaviors. The integration of the unconscious habits into consciousness leads to the production of meanings and the potential change in one's habitual ways of thinking, feeling, and behaving as outcomes of the analytic process.

The archetypal images are signs as the vehicles for/of information embedded in the collective unconscious, and the unconscious is capable of spontaneously producing images "irrespective of wishes and fears of the conscious mind" (Jung CW 11: 745). Jungian archetypes do provide a psychological ground for Peircean habits. Never mind their status as ideas, or rather because they are indeed regulative and generative ideas, archetypes as symbols of transformation are effective in the physical world. For Peirce too, ideas play a part in the real world. Thus Jungian psychology, both theoretically and practically, constitutes a specific method that accords with Peirce's pragmatic maxim: "Consider what effects, that might conceivably have practical bearings, we conceive the object of our conception to have. Then our conception of these effects is the whole of our conception of the object" (CP 5.402).

Archetypal ideas, according to contemporary post-Jungians, are considered to be both the structuring patterns of the psyche and the dynamical units of information. A key element in post-Jungian psychology is the balance between integration and some fragmented complexes that constitute one's psyche. Individuation involves a conscious awareness about a possible conflict between many complementary opposites in an individual psyche rather than a simple elimination of a conflict. Jung is viewed as a system-theorist, and such an approach implies that the realms of both interpersonal and intra-psychic realities are connected by means of a seamless field of symbolic references that Peirce would have called semiosis. The relationship between the collective unconscious and the personal consciousness was of the utmost importance for Jung. Signs are "always grounded in the unconscious archetype, but their manifest forms are molded by the ideas acquired by the conscious mind. The archetypes [as] ... structural elements of the psyche ... possess a certain autonomy and specific energy which enables them to attract, out of the conscious mind, those contents which are better suited to themselves" (Jung CW 5: 232), that is, as Peirce would have said, potentially "connected with in representation" (CP 5.285). 
According to Peirce, signs grow and become other and more fully developed signs. As embedded in a stream of semiosis, we too are signs and we can acquire information and come to mean more than before: we individuate! Indeed, the mediatory aspect functions as to empower or strengthen the ego (cf. Samuels 1985) on its road toward an individuated Self. Jung's position is prospective in his saying that "the archetype determines the nature of the configurational process and the course it will follow, with seeming foreknowledge, or as if it were already in a possession of the goal" (Jung $C W$ 8: 411). The synthesis of past, present and future inscribed in the collective unconscious as the universal memory pool accords with Peirce's semiosis acting within a shared layer of human experiences: "A man denotes whatever is the object of his attention at the moment; he connotes whatever he knows or feels of this object, and is the incarnation of this form ...; his interpretant is the future memory of this cognition, his future self" (CP 7.591).

The past and future memories are embedded in the realm of images comprising the objective psyche. In semiotic terms, archetype is a symbol of transformation, and symbols themselves act as transformers capable of raising unconscious contents to the level of consciousness. As noted by Noth in his Handbook of semiotics, symbols for Jung are "the conscious forms given to the unconscious archetypes to which we have no direct access" (Noth 1995: 120). Indirectly, though, they can be communicated by being mediated or interpreted, and Tarot images perform an amplifying function in agreement with Jungian synthetic method that implies the emergence of new meanings as carrying the utmost significance. Synthetic method reflects the future-oriented path to knowledge and for Jung, as for Peirce, "psychological fact ... as a living phenomenon ... is always indissolubly bound up with the continuity of the vital process, so that it is not only something evolved but also continually evolving and creative" (Jung CW 6: 717). Moreover, Jung defining the collective unconscious as the objective psyche outside the actual personal experience and his notion of the archetypes that appear as mental representations of an object even if the latter seems to be "a pure fiction" (CP 4.351), as if a figment of our imagination - describe "the Reality which by some means contrives to determine the Sign to its Representation" ( $C P$ 4.536); this is the psychic reality, for Jung.

The archetypes are general tendencies and exist in potentia only. The skeletal concepts, their meanings and significance are not exhausted by Platonic Ideas: true, they are forms without content, indicating a possibility of a certain type of perception and action only potentially. But the vague and unconscious forms, as Firsts, are to be filled with contents. Situated in the midst of the Peircean Seconds, within real flesh-and-blood 
human experiences, they need thought and interpretation as Thirds so as to acquire meaning by virtue of being "altered by becoming conscious and by being perceived" (Jung in Pauli 1994: 159). The plurality of evolving meanings finds their expressions in the symbols of transformation: a symbol "points beyond itself to a meaning that is ... still beyond our grasp, and cannot be adequately expressed in the familiar words of our language" (Jung in Noth 1995: 119) but needs a medium or representation - like Tarot pictures - for its very expression.

Transformation of old habits means "a modification of a person's tendencies toward action" (CP 5.476) - such a modification being the ultimate purpose of the reading process. Habits, however, are resilient they wouldn't be habits otherwise - and their action is similar to the action of the archetypes that, according to Jung, can often possess the psyche in a guise of the unconscious Shadow (akin to the icon of "The Devil" in a Tarot deck), or Persona ("The Pope" or "Hierophant"), or Anima/ Animus ("The Empress" and "The Emperor"), or the Eternal Child ("The Fool"). In a Tarot deck, "The Fool" is the first unnumbered card (zero): it is the very start of the individuation process that culminates in the archetype of the Self represented by the final card numbered twenty-one, called "The World" or "The Universe." The circular shape on "The World" picture expresses a continuum, that is, the never-ending search for meanings in the changing circumstances of experience. The imagery of "The World" represents the ideally individuated personality: personal wholeness and oneness with "The World" is an ideal limit, and the Fool's journey will have to start anew from zero even as in each cycle our consciousness expands to accommodate new meanings and new experiences. What Peirce called a man-sign, indeed acquires more information, hence a sense of meaning and significance.

In order to go ahead, each one of us has to often leave behind some illusions and dependencies that are counterproductive to human growth and spiritual development: to learn many life lessons. These symbolic lessons are embedded in the constellations of the cards. Nearly every one of the cards has an image of a living being, a human figure situated in different contexts. This figure is not just a physical body but mind, soul, and spirit as well - a multimodal sign. And while a body goes through life and accomplishes different tasks, the human psyche too goes through transformations as life itself calls for the constant renewal and enlargement of our consciousness. The journey through the cards' imagery is therapeutic as each new life experience contributes to self-understanding and, ultimately, spiritual rebirth. In the Tarot deck, the archetype of Rebirth is signified by "The Sun" card, with its image of a small child warming in the sunshine, the psychic energy of a child enriched by the 


\section{I. Semetsky}

solar energy of the whole universe: it represents the Jungian archetype of the Divine Child.

\section{Tarot typology}

The four suits in the Tarot are connected to four ancient elements: pentacles to earth, wands to fire, swords to air, and cups to water, and relate to four Jungian psychological functions: sensing, feeling, thinking, intuiting. One of the most popular spreads is called The Celtic Cross (Figure 2): it comprises ten positions that are combined together to provide information illuminating a particular problematic.

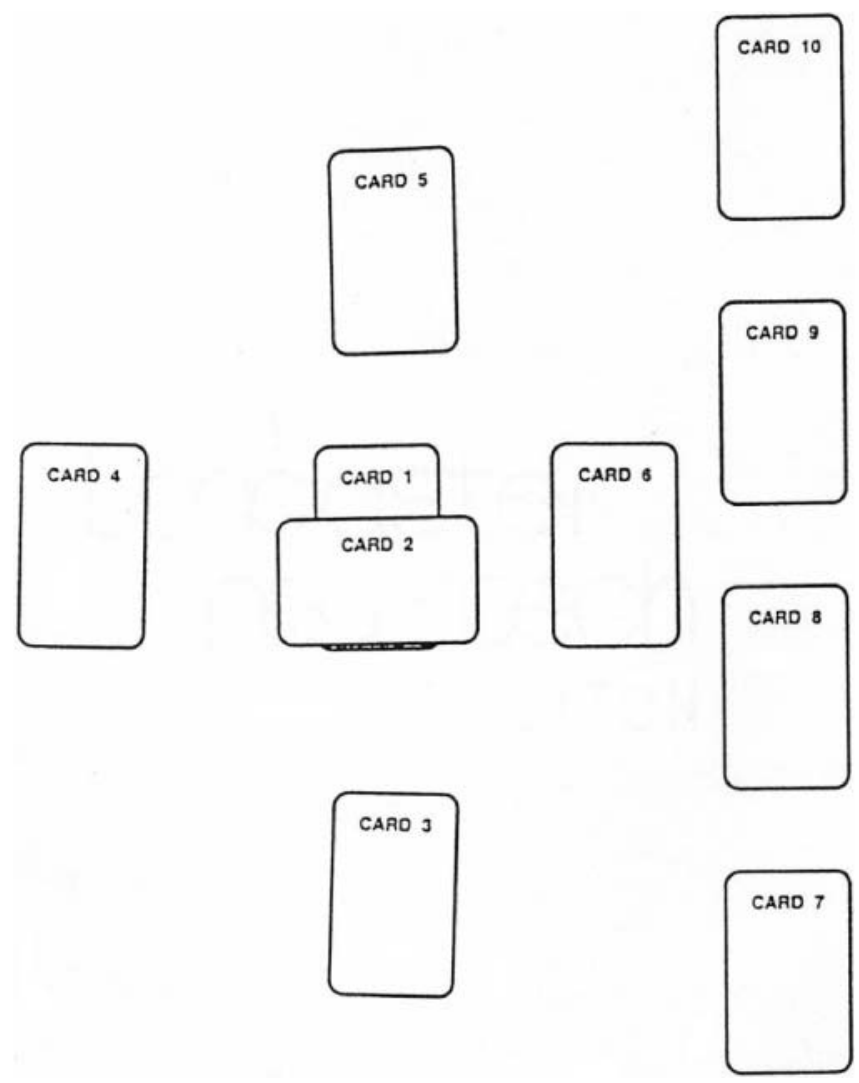

Figure 2. The Celtic cross spread 
Some positions in a spread signify the dimension of time; that's why there can be a peculiar feeling of gazing into the future and revisiting the past during readings. The metaphysics of time in a spread reflects a fourdimensional view, in which past, present and future events coexist. David Bohm, a physicist, has posited all events as enfolded in the timeless implicate order. In the physical world they unfold into explicate order thereby creating time in our customary three-dimensional reality. During readings, when the cards are being spread in a layout that comprises positions signifying all three aspects of time simultaneously, human perception encompasses both the past and (paradoxically) future memories (Semetsky 2003a) compressed in the here-and-now of each reading. Hillman (1972) believes that the art of memory serves as a method for presenting the organization of the collective unconscious. As a book "written" in pictorial signs, the Tarot spread can be narrated, that is, read and interpreted. The numerical growth from Ace to ten represents the progressive mastery of a problematic situation, even when encountering a temporary defeat, as a lesson to be learned, that may be connoted by some of the cards. Predominance of any one suit in the spread is an index of the general emotional or mental state of the subject of a particular reading. What is a dominant affect? Is she emotional? Is she in his intellectual best or worst? Is she in touch with her feelings? What mood does she demonstrate? Does she have any insight? What bothers her most: the earthy practical matter or heavy emotional burden?

The cards of Minor Arcana carry messages of feeling happy or depressed, overwhelmed with stress or experiencing ecstatic joy. They encourage us to take new actions or recommend contemplation and rest; they point towards getting out of stormy waters or being unjustly manipulated; finding a lasting relationship or being dissatisfied with the results of an enterprise; surrendering one's power or experiencing the reversal of fortune. The dynamics never stops: pictures tell us multiple stories about making plans or breaking promises; winning or losing; experiencing separation anxiety or preparing for a marriage; falling in love or getting out of an abusive relationship; starting a new venture or facing financial difficulties. As embedded in the universality of Tarot themes they necessarily assert basic human values as cross-cultural. These values are derived from human experiences that transcend cultural or language barriers and represent such common themes as birth, death, love, separation, or the moral virtues of temperance, prudence, honesty, love, and so forth; all "inhabiting" the collective unconscious. Yet, the ever-expanding multiplicity of experiential situations and events may always present new challenges. The following case study is such an example. 


\section{A case study}

Marina was a white professional woman, thirty years old. Her reason for a reading was a relationship problem; this was the only information before the reading began. She wanted to gain insight into present, future, herself and significant others. She also wanted to clarify issues and to gain self-understanding during this important period of her life. Her layout is shown here ${ }^{4}$ (Figure 3 ) in the format of the basic Celtic Cross spread as per Figure 2, but with several additional cards in various positions that have provided an important supplementary information.

The first card, the Ten of Cups, was crossed by the Ten of Swords in the second position, indicating that at the present time the happy committed relationship was coming to an end thus making Marina feel that everything was ruined in her life and bringing her to the threshold of depression. Marina said at this point that this relationship lasted three years and she had married her spouse just a few months ago. The grim-looking Ten of Swords, however, signified not only the end in the relationship, but also the cut-off of an erroneous or false way of Marina's own perception of this situation. Perhaps the relationship lasted relatively long because Marina had taken a point of view that let her to stay in the status quo during this time. Three cards (instead of one) as a numerological reinforcement of the third position indicated a strong urge to become aware of the unconscious motivations and issues Marina was overwhelmed with. The prevailed suit was that of swords. Was it Marina's own typology? Not exactly. But the multiplicity of swords indicated a number of complexes and splinter psyches tormenting Marina and destroying her sense of self.

The King of Swords in the fourth position depicted the character of her spouse, Marina's own personality being to a certain extent dissolved in that of her husband, making the co-dependency issues the central theme of this reading. The Devil (in the extra eleventh position) has confirmed the presence of the Jungian archetype of the Shadow as a defining factor in Marina's situation. An authoritative and controlling person (The King of Swords), Marina's spouse had influenced her life and psyche in the past to such an extent that it still persisted in the present. The immediate future however, indicated the collapse of a structure as it existed so far, as represented by the image of The Tower, an archetypal temenos, in the sixth position. The original meaning of temenos in Greek is a sacred precinct like a temple; a synonym for it is a hermetically sealed vessel or, for that matter, the Tower that was sealed at the top prior to be struck by a symbolic lightening from above. Temenos, as employed in Jungian analysis, has acquired psychological connotations as the psychically charged 
Marina
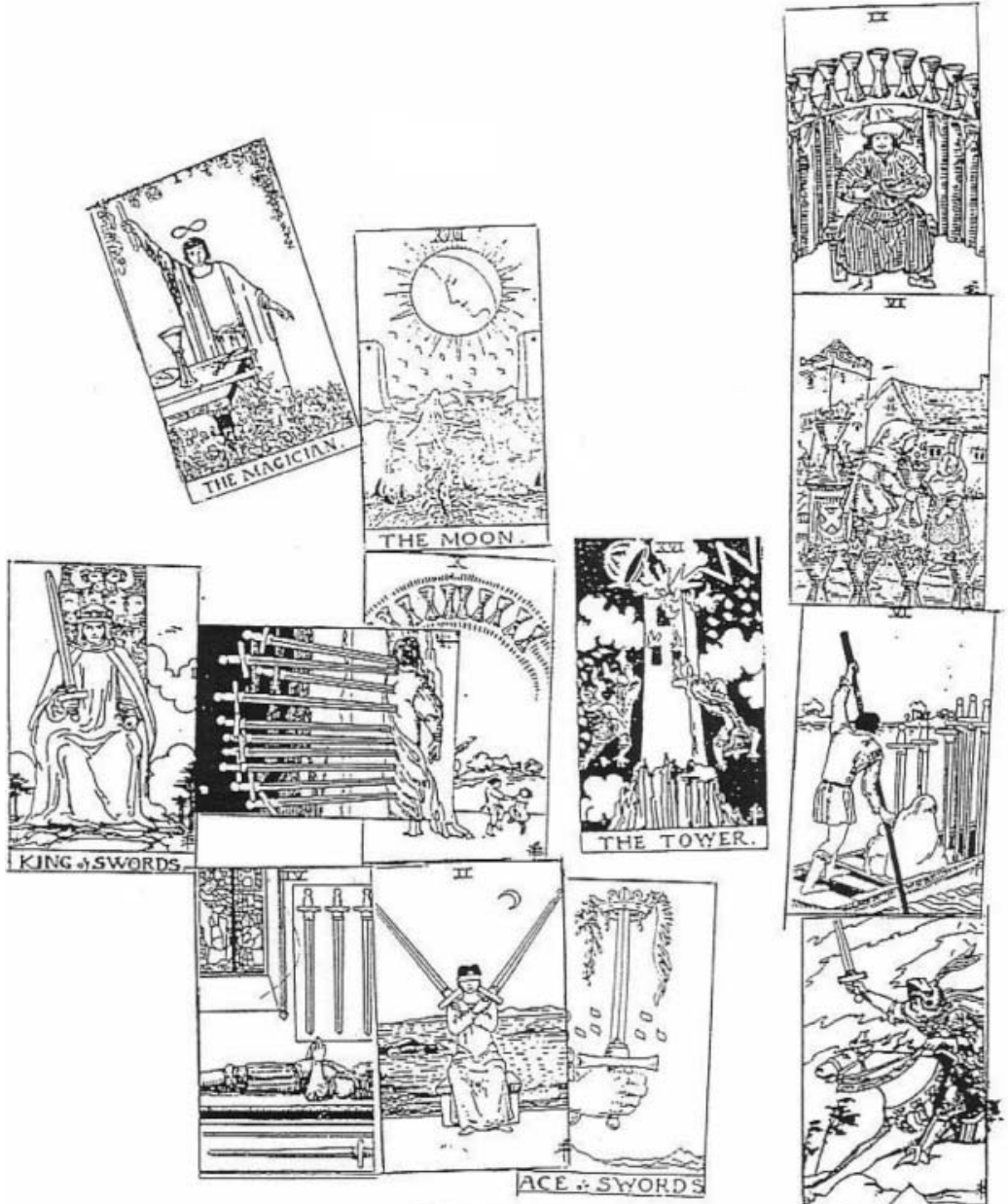

2 $2 x+535$

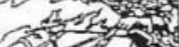

$=2$ en
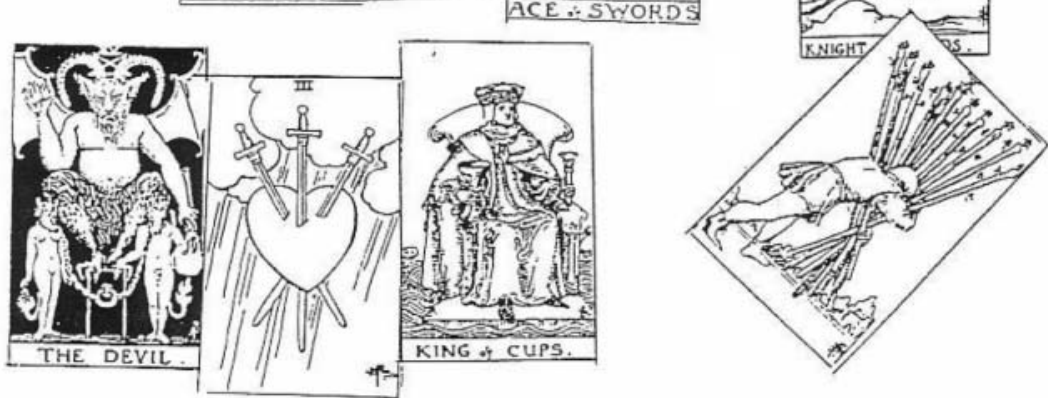

Figure 3. Marina's layout 
area surrounding a complex that can be experienced through the symbolism of any closed container such as a womb, a prison, or for that matter, The Tower.

Until now, Marina had been procrastinating, in an impasse, and unable to decide for herself where to turn and in which way to move (the Four of Swords and the Two of Swords in the third position). She was so frightened, or lacked confidence to such an extent that her actions (the Ace of Swords) were self-defeating, leading to the creation of further confusion and fogginess around her. This message was reinforced by The Moon in the fifth position carrying the information that if Marina continued the course of action she currently pursued, believing that by not confronting the issues at hand they might go away by themselves, it would have become a road to self-deception. The probability of the archetypal influence of The Moon was the warning sign that Marina's distress might grow into a clinical depression or even affective disorder if not addressed. At this point, Marina stated that she had been confronting her husband, but that he did not seem to understand her point. But of course. He chose not to understand, and Marina accepted the situation, the conflict thus having reached an impasse (the Two of Swords). Marina was overwhelmed with stress and felt helpless, the burden coming to the limit of what she could bear (the Ten of Wands in the fourteenth position) embedded in the conflicting emotions and contradictory thoughts. She hardly coped with the load of contradictions that were contributing to her symbolic imprisonment in The Tower, ${ }^{5}$ connoting the meaning of the breakdown. But the position of The Tower in Marina's immediate (!) future suggested that the weight on her shoulders is soon to be lifted, and the reason for that should be Marina's sudden awareness and the expansion of consciousness precisely because of the breakdown.

This moment became the turning point of the session. Although at the time of laying down the cards Marina's thoughts were centering on wanting her husband to reach for her, to approach her (The Knight of Swords in the seventh position) while both hoping for and being anxious to implement the nostalgic fantasy of being sweethearts in the sharing and trustful relationship (the Six of Cups in the ninth position) - the resolution of this contradiction was about to occur! In fact, the eleventh (supplementary) constellation of the cards - The Three of Swords between The Devil and the King of Cups - was an index (as Peirce would have said) of an emotional pattern in the past that has had a tendency to replicate itself. The unresolved complex of co-dependency or attachmentseparation issues (The Devil) has led to the painful separation (The Three of Swords) with a person who in fact deserved full trust and unconditional love (The King of Cups). This event caused Marina her "broken 
heart" (The Three of Swords, almost literary). The fantasy will have indeed become a reality for Marina, but only after her understanding that it is she who has to make a decisive step. Such was a message of The Tower in the position of immediate future as a symbol of "breaking" turning into the "making" - the making of Marina's "Self" as "self-making," the unconscious becoming conscious in the individuation process.

Indeed, each Jungian archetype has both dark and light aspects, and the symbolism of The Tower (Semetsky 2006b) is particularly poignant in this regard. Symbolic thunder and lightning from above, by breaking the order of things and so negating the stasis of one's identity within the existing order, simultaneously illuminates the way to the new order and new identity, thus not only breaking the old but also creating the new: Marina as her-Self! At this point Marina, unable any more to contain the torment of her bleeding heart (the Three of Swords in the eleventh position), flooded in word associations thus manifesting the catharsis (The Tower) that was just about to take place. Her psyche was freeing herself from the chains of The Devil; her weak ego was getting out of the Shadow of fear and dependency toward the individuation of her Self.

Marina mentioned at this point that in discussing birth control methods, she and her spouse came to a mutual decision of using condoms. But was it really a mutual decision, or only apparently mutual? Marina admitted it was his decision accepted passively by her. Marina said, however, that she was a fertility specialist; the conflict was thus based on her being fully aware of her cycle, but having been enslaved by The Devil - under the influence of the Shadow-projection from her husband - she felt immobilized (The Two of Swords) and unable to persist in her attempts to communicate her preference to her husband. He, being in the archetypal image of The King of Swords, was likely a personality not in touch with his feelings. Had he ever demonstrated his feelings? Marina said that only once and he could not cope and broke down in sobs. Indeed! The King of Swords is a personality that has its own projections at a deeper archetypal level, such as Jungian Persona. The time allotted for the reading (fifty minutes) did not allow for further exploration of this issue, but the fact that Marina's husband was insisting on condoms carried a message of a person who was scared of intimacy, like The King of Swords can easily be. The body and bodily contacts (earth) are not something that The King of Swords (air) would prefer. So Marina's husband could have easily projected his own inferior part onto her, and although she was seeking counselling, he wanted to just stay in the image of the King of Swords!

The Six of Swords in the eighth position indicated that there was a tendency of getting out of the troubled waters of a stormy relationship 
toward achieving a sense of harmony. This card denoted a sense of reconciliation and a release of tension and anxiety after a period of strain in Marina's immediate environment, further reinforced by the reassurance of the Nine of Cups in the tenth position. This "outcome" card conveyed the meaning of emotional security and the feeling of content, the wish fulfilled and the desires coming true - provided of course Marina is to become aware of her unconscious! And in order to become aware, she is to go through the realization of the actualized Tower with its rapid and sudden cognitive, emotional and spiritual awakening - the process that started to take place in the here-and-now of the reading. Marina was going through the process of realization with obvious pain (the presence of the Three of Swords!) but also being newly empowered by this insight. Associating with the images on the cards in front of her, she said that she would like to go to a conference, to be away for four days and that her spouse was against it, telling her not to go and that he would miss her. It sounded rather manipulative, but very much in the framework of the King of Swords with his inquisitive mind and controlling attitude. On her side Marina feared, she said, that he might find somebody else. In four days!? Well, thus spoke The Devil, manifesting Marina's deep anxiety and co-dependency, and the time came to break away from his bondage.

Interpreting the symbolism of The Devil to Marina led to new themes emerging from the spread, like Marina's low self-esteem, lack of confidence and the deeply hidden fear of abandonment and a separation anxiety (supported, sure enough, by the unfinished business as per imagery of the three cards in the eleventh position). Marina's said afterwards that she made a decision and would go. This dynamics was also visible in the Six of Swords: the symbolic movement towards calmer waters was to be actualized in the real travel Marina was about to undertake, the latter in turn "causing" the relationship with her husband to move forward and improve. On my suggestion, Marina picked up one card to probe the "attitude" and get a possible advice from the collective unconscious. The Magician, the teacher-guide, the very antithesis of The Devil, was thus communicating the message of a lesson that Marina was to learn in the school of life. The Magician is the archetype of the Trickster, but at a deeper level he is a figure of Hermes, the god of communication and quick action (Semetsky 2003b) that has revealed to Marina her real potential and encouraged her in pursuit of goals and the ability to take an initiative in her hands. The archetypal energy now available for Marina was one of action, purpose and will. Her consciousness was literally rising from the hell of The Devil to the heaven of The Magician. 


\section{Concluding remarks}

Marina answered yes to the question of whether this reading had contributed to achieving her purpose, stating in writing: "It allowed me to conceptualize the polarities in a way that I can use to help myself grow and gain heart... and go to the next cycle." She wanted to have a follow-up session and explained it by stating, "to continue the Tarot clarification as I move into the new cycle." The reading was significant and meaningful to Marina and she wrote, "Very helpful! It redeemed me from a state of shock and promoted my strength." She provided the following overall comment: "Important and skilled work! A much needed type of guidance and counseling that is multifaceted engagement of the psyche." Tarot symbols do have a healing and transformative potential because they create a semiotic bridge between the unconscious archetypes as the universals of human experiences and the conscious mind. The art of interpretation - a Tarot reading - has transformed the chaos of Marina's individual perceptions into a meaningful pattern of experiences that became literally visible to her in the format of pictorial images as the reading unfolded and an unorthodox communication was established.

Peirce refused to "conceive of the psychical and the physical aspect of matter as two aspects absolutely distinct" ( $C P$ 6.268). His holism implies the coordination between the two different aspects of one total process that, as this paper has demonstrated, finds it expression in the Tarot semiotic system. The process of reading signs has as its basis a specific mode of inference: abduction. All cognition, for Peirce, is sign-mediated, however the Firstness of abduction is presented in an instance and is directly had prior to the Thirdness of mediation. Abductive inference, which "is subconscious ... [and] does not have to make separate acts of inference but performs its acts in one continuous process" (EP 2: 227), blends into a perceptual judgment. Abduction does seem to function instantaneously not because there is no temporal interval of inference, but because the mind remains unaware of when it begins or ends: psychological immediacy and logical mediation constitute what Peirce has called a "mediated immediacy" ( $C P$ 5.181) that defies a purely logical explanation. It is amenable to a clear insight, therefore becoming conscious: sure enough, the abductive suggestion "comes to us as a flash. It is an act of insight" (CP 5.181). Albeit fallible, it still has a mysterious power "of guessing right" (CP 6.530). The interpretation (Thirdness) involves a series of abductive guesses (Firstness-in-Thirdness), and the explication of the implicit meanings has, in accord with Peirce's pragmatic maxim, profound implications at the physical and mental levels as the process of semiosis unfolds in front of our very eyes. 
At the semiotic level of the real and "physically efficient" ( $C P$ 5.431) generals as the Jungian archetypes of the collective unconscious, a hypothetical idea constitutes what Peirce called a psychological ground for a habit that carries a flavour of anticipation: it "is already determinative of acts in the future to an extent to which it is not now conscious" ( $C P$ 6.156). In this respect the pictorial cards are capable of positing that what was always already presupposed (cf. Deely 2001) and what constitutes the informational content "encoded" in the image. By becoming aware of her not-yet-fully- realized habitual actions taken under the influence of the unconscious archetypes, Marina's Tarot reading not only contributed to healing her psyche but has also empowered her with the ability to look reflectively at herself and her significant other. Despite (or perhaps due to) her confusing and painful experiences, Marina achieved the level of self-awareness that empowered her with the ability to choose actions that would have remained "taboo" for her if not for the transformative effect of the healing art of Tarot symbolism that has enabled habit-change! To achieve emotional security and the peace of mind means to continuously work on expanding the boundaries of one's consciousness. The life of such a person, for Jung, will have had wholeness and completeness, a satisfaction, and an emotional balance. A decisive step towards such balance was taken by Marina, indeed!

\section{Notes}

* A much abbreviated version of this paper, under the title "The healing art of Tarot symbolism: a case study" was orally presented at the Semiotic Society of America Annual Meeting "Semiotics and survival," New Orleans, 4-7 October 2007. Thank you to all participants in the session "The art of survival: Transformation, healing, and self-knowledge," chaired by Elka Kazmeirczak.

1. An earlier brief mention of "Marina's" case, as well as of fourteen other clinical casestudies, has been made in Semetsky (2005).

2. On projection, see Semetsky (2006c).

3. Acknowledgment: I first conceptualized the affinities between Jung, Peirce and the Tarot in Semesky (2001).

4. All cards reproduced in this layout as per Figure 3 are subject to the copyright as following: "Illustration is from Rider-Waite Tarot Deck, known also as the Rider Tarot and the Waite Tarot. Reproduced by permission of US Games Systems Inc., Stamford, CT 06902, USA. Copyright 1971 by US Games Systems, Inc. Further reproduction prohibited"

5. Jung, non-incidentally, used the notion of contradiction with regard to the meaning of the tower which he, at a symbolic level, identified with the Tower of Babel, that is, a symbol of false omnipotence and mistaken certainty, a priori condemned to destruction during the most powerful and confusing instance of the persisting contradiction. 


\section{References}

Deely, J. 2001. Four ages of understanding. Toronto: University of Toronto Press.

Gad, I. 1994. Tarot and individuation. York Beach, ME: Nicholas-Hays.

Hillman, J. 1972. The myth of analysis. New York: Harper \& Row.

Jung, C. G. 1953-1979. Collected works, vols. 1-20, H. Read, M. Fordham, G. Adler, \&

W. McGuire (eds.), R. Hull (trans.). Princeton, NJ: Princeton University Press.

Jung, C. G. 1959. The archetypes of the collective unconscious. London: Routledge.

Nichols, S. 1980. Jung and tarot: An archetypal journey. York Beach, ME: Samuel Weiser.

Noth, W. 1995. Handbook of semiotics. Bloomington: Indiana University Press.

Pauli, W. 1994. Writings on physics and philosophy, Charles P. Enz \& Karl von Meyenn (eds.), R. Schlapp (trans.). Berlin: Springer-Verlag.

Peirce, Charles S. 1931-1966. The collected papers of Charles S. Peirce, 8 vols., C. Hartshorne, P. Weiss, and A. W. Burks (eds.). Cambridge: Harvard University Press. [Reference to Peirce's papers will be designated CP followed by volume and paragraph number.]

Peirce, Charles S. 1998. Essential Peirce: Selected Philosophical Writings, vol. 2, Peirce Edition Project (eds.). Bloomington: Indiana University Press. [Reference to Essential Peirce will be designated EP followed by volume and page number.]

Samuels, A. 1985. Jung and the post-Jungians. London \& New York: Routledge.

Samuels A., B. Shorter \& F. Plaut. 1986. A critical dictionary of Jungian analysis. London \& New York: Routledge.

Semetsky, I. 2001. Signs in action: Tarot as a self-organized system. Special issue, Cybernetics \& Human Knowing 8(1-2). 111-132.

Semetsky, I. 2003a. Memories of the past, memories of the future: Semiotics and the tarot. Applied Semiotics / Sémiotique appliquée 13. http://www.chass.utoronto.ca/french/as-sa/ ASSA-No13/Article6en.html (accessed 27 March 2009).

Semetsky, I. 2003b. The magician's autopoietic action, or Eros contained and uncontained. Trickster's Way 2(3). http://www.trinity.edu/org/tricksters/TrixWay (accessed 27 March 2009).

Semetsky, I. 2005. Integrating Tarot readings into counselling and psychotherapy. Spirituality and Health International 6(2). 81-94.

Semetsky, I. 2006a. The language of signs: Semiosis and the memories of the future. SOPHIA 45(1). 95-116.

Semetsky, I. 2006b. Semanalyisis in the age of abjection. Applied Semiotics / Sémiotique appliquée 17. http://www.chass.utoronto.ca/french/as-sa/ASSA-No17/Article5en.html (accessed 27 March 2009).

Semetsky, I. (2006c). Tarot as a projective technique. Spirituality and Health International 7(4). 187-197.

Inna Semetsky (b. 1948) is a research academic at University of Newcastle <inna.semetsky@ newcastle.edu.au $\rangle$. Her research interests include philosophy of education, semiotics, and systems theory. Her recent publications include Deleuze, education, and becoming (2006); "Towards a semiotic theory of learning: Deleuze's philosophy and educational experience" (2007); "Sem-analyzing events: towards a cultural pedagogy of hope" (2007); and "On the creative logic of education, or: re-reading Dewey through the lens of complexity science" (2008). 